\title{
IMPLANTAÇÃO DO SISTEMA 5S NA GESTÃO DE ARQUIVOS
}

\author{
DEPLOYMENT OF 5S SYSTEM IN ARCHIVES MANAGEMENT
}

\author{
Marcelo Cavaglieri \\ SENAC \\ Jordan Paulesky Juliani \\ UDESC
}

\begin{abstract}
RESUMO
Uma gestão documental eficiente traz diversos benefícios, não apenas ao profissional, mas, principalmente, aos gestores das empresas que podem usufruir de tais informações nas tomadas de decisão para desfrutar de vantagens competitivas acerca dos concorrentes. Tendo em vista que a eficácia é uma busca constante de qualquer empresa a fim de atingir os objetivos estratégicos e melhorar as técnicas que possibilitem mais produtividade com o uso de menos recursos financeiros. Nesse sentido, buscou-se aplicar a filosofia 5S na gestão de arquivos do Grupo Santa Fé, uma vez que é preciso melhorar os processos atuais, com menos desperdícios e mais eficiência, tendo em vista a necessidade de atender o cliente com mais eficácia diante de suas necessidades informacionais. Quanto ao método utilizado, caracteriza-se por ser uma pesquisa-ação, de abordagem qualiquantitativa, classificada como exploratória e descritiva. Entre os resultados obtidos da pesquisa realizada, destaca-se, de forma quantitativa, a redução de desperdícios com ganhos significativos do Lead Time, diminuindo o tempo gasto para processar as atividades. Ganhos financeiros também foram obtidos, com mais aproveitamento dos recursos e uma reformulação na forma de guardar os documentos. De forma qualitativa, destaca-se um melhor ambiente de trabalho e aumento da eficiência do serviço prestado, gerando mais satisfação do cliente.
\end{abstract}

Palavras-chave: Arquivo empresarial. Gestão documental. Gestão da informação. $5 S$.

\section{ABSTRACT}

An efficient document management brings various benefits, not only for professionals of the area but, mainly, for business managers who can use this information in their decisionmaking to enjoy competitive advantages on competitors. Having in mind that effectiveness is a constant pursuit for any company in order to achieve their strategic goals and improve the techniques which enable more productivity using fewer financial resources. In this sense, it was sought to apply the $5 \mathrm{~S}$ philosophy in the document file management of Santa Fé Company, once it is necessary to improve the current processes with less waste and more efficiency, with a view to the need to suit the client more efficiently before their information necessities. Regarding to the method used, it is characterized as a researchaction in a quali-quantitative approach, classified as exploratory and descriptive. Among the obtained research results, it stands out in a quantitative way the reduction of waste, with significant gains of Lead Time, diminishing the time to process the activities. Financial gains were also obtained with a better use of resources and a redesigning of the way to keeping the documents. In a qualitative way, a better working environment is highlighted and increase of the service efficiency in bringing more customer satisfaction.

Keywords: Company Archives. Document Management. Information Management. 5S. 


\section{INTRODUÇÃO}

Por muito tempo prevaleceu o entendimento de que os arquivos empresariais eram apenas um setor do depósito de documentos e, eventualmente, eram utilizados para comprovar alguma transação em caso de fiscalização. Com a atribuição da devida importância à informação no processo decisório das organizações, o papel do arquivo nas empresas foi substancialmente modificado. Logo, deixou de ser um simples depósito de documentos para se tornar um setor estratégico, capaz de organizar, armazenar e processar informações utilizadas pelos diversos setores da empresa para a realização de suas atividades. Percebeu-se que as informações arquivadas poderiam ser estrategicamente utilizadas pela empresa, permitindo aos gestores tomarem decisões mais acertadas. Neste cenário, o arquivo passa a ser entendido como uma fonte de informações valiosas e confiáveis, que vai nortear decisões de planejamento e ações gerenciais.

A necessidade de gerir informação de maneira eficaz é uma preocupação de empresas de diversos segmentos e portes, uma vez que a gestão inadequada de seus documentos conduz a situações de risco fiscal, trabalhista, previdenciário e cível. Tais situações podem ser evitadas por meio de uma gestão documental, que vai zelar e tratar os documentos nas fases corrente, intermediária e permanente, de forma a obter um controle adequado desde a criação do documento até a sua eliminação.

Observando a necessidade da gestão eficiente dos arquivos, especialmente no que se refere ao processo de recuperação da informação, buscou-se, por meio desta pesquisa, localizar, a partir de um levantamento bibliográfico, modelos e ferramentas de gestão compatíveis às mudanças que precisam ser feitas para tornar o arquivo mais eficiente. Foi encontrada na filosofia 5S a especificação de uma forma de trabalho que propõe uma organização do ambiente mais eficiente e, por consequência, dos documentos manipulados pelas organizações.

O 5S é uma filosofia que busca uma mudança de qualidade nas atividades diárias dos colaboradores, possibilitando um planejamento sistemático de classificação, ordem, limpeza e destinação adequada de materiais. Segundo Liker e Hoseus (2009), o 5S cria um padrão para o primeiro passo da solução de problemas, que é o alicerce para o estabelecimento de um ambiente de trabalho adequado para todos os membros da equipe. Isso possibilita, de imediato, maior produtividade, segurança, clima 
organizacional, motivação dos funcionários e consequente melhoria da competitividade organizacional.

Esta pesquisa foi realizada no arquivo das empresas do Grupo Santa Fé. Atualmente, o Grupo perfaz onze empresas ativas nas áreas de comercialização de veículos, administração de consórcios, construção civil, hotelaria e administração de shopping centers.

Com a aplicação da filosofia 5S, investigou-se a solução de alguns problemas vivenciados no arquivo, relacionados à demora de recuperar documentos e à falta de organização física dos documentos e do espaço físico.

A formulação do problema deste estudo está na aplicação dos conceitos do $5 \mathrm{~S}$ em um ambiente distante da aplicação usual. Neste sentido, pretende-se responder à seguinte questão de pesquisa: como aplicar o 5S na gestão de arquivos? A questão de pesquisa retrata uma problemática voltada às melhorias necessárias à gestão de arquivos, pois, com a massa documental cada vez maior, a gestão se torna desafiadora, e novas técnicas devem ser implantadas para garantir o sucesso e o bom funcionamento desses ambientes.

O objetivo geral da pesquisa é aplicar o $5 \mathrm{~S}$ na gestão de arquivos. Já os objetivos específicos são:
a) atender com mais rapidez os pedidos de recuperação dos documentos;
b) melhorar a organização do espaço físico;
c) melhorar o ambiente de trabalho;
d) reduzir o tempo destinado ao armazenamento dos documentos;
e) avaliar os resultados da aplicação do 5S na gestão do arquivo do Grupo Santa Fé.

\section{GESTÃO DOCUMENTAL}

Apesar das técnicas de gestão documental serem antigas, elas foram efetivamente inseridas nas empresas a partir do final do século $\mathrm{XX}$, quando o número de empresas cresceu e, por consequência, o volume de documentos manipulado por estas.

Nishitani (2010) destaca que o termo "gestão de documentos" surgiu de forma mais contundente apenas no final da década de 1940, a partir de reformas administrativas ocorridas nos Estados Unidos e Canadá. Após esse período, buscou-se 
maior eficácia na produção, manutenção, utilização e alocação final dos documentos, pois se percebeu a impossibilidade de lidar, de acordo com os moldes tradicionais, com a massa documental que estava sendo produzida pelas organizações e, com isso, novas práticas de avaliação, seleção e eliminação de documentos de arquivo começaram a ser estruturadas.

As empresas começaram, gradativamente, a valorizar os documentos produzidos internamente. Isto aconteceu pela necessidade de informações estratégicas para orientar suas decisões, ou devido às fiscalizações, que as obrigavam a organizar adequadamente sua massa documental. Como consequência, as empresas optaram pela contratação de profissionais qualificados para cuidar da gestão dos documentos, facilitando, assim, o processo de recuperação dos mesmos.

Tendo em vista a preocupação dos empresários e o crescimento da oferta de profissionais arquivistas no mercado, o processo de gestão documental tornou-se mais efetivo nas empresas, independente de seu segmento ou porte. Para melhor entendimento dessa atividade, busca-se o suporte conceitual na Lei brasileira n. 8.159, que define, no artigo 3ำ, a gestão documental como sendo:

[...] o conjunto de procedimentos e operações técnicas referentes à sua produção, tramitação, uso, avaliação e arquivamento em fase corrente e intermediária, visando a sua eliminação ou recolhimento para guarda permanente. (BRASIL, 1991, p. 1).

Em consonância, o CONARQ (2006, p. 15) destaca que a gestão documental trata de "[...] documentos produzidos e recebidos no decorrer das atividades de um órgão ou entidade, independente do suporte em que se apresentam, registram as políticas, funções e decisões".

No entendimento de Valentim (2012), a gestão documental é parte da gestão da informação e pode ser definida como o conjunto de atividades documentais integradas com foco na informação arquivística, pois esta contempla todo e qualquer tipo de informação existente no ambiente organizacional.

Para Moreno e Bartalo (2008, p. 73), "um dos componentes da gestão da informação é a gestão documental, que amplia a capacidade da gestão administrativa". A gestão de documentos pode auxiliar o diagnóstico organizacional, pois surge como uma ferramenta indispensável à otimização do uso das informações contidas nos mais variados suportes para os variados níveis da organização. 
A informação estruturada e organizada é fundamental e indispensável às organizações que desejam entrar e competir no mundo globalizado. Para que a informação possa ser acessível, é preciso trabalhar rigorosamente as três principais fases da gestão de documentos descritas por Paes (2004):

- produção de documentos: é uma atividade relacionada à elaboração de documentos em decorrência das atividades de um órgão ou setor de determinada instituição. Nesta fase, o profissional responsável pelo arquivo, seja um bibliotecário ou arquivista, deve contribuir para que sejam criados apenas documentos essenciais à administração, orientando e padronizando a redação de documentos oficiais, bem como a forma e a estrutura dos documentos produzidos;

- utilização de documentos: refere-se ao recebimento, classificação, registro, distribuição, empréstimo e recuperação da informação dos documentos;

- destinação dos documentos: diz respeito às atividades de análise, seleção e definição de prazos para o armazenamento dos documentos. Para isso, é necessário conhecer a legislação vigente, para fixar o tempo de conservação de cada documento, e, também, o ramo de atividade, a missão e os objetivos da empresa.

Nas fases de gestão dos documentos, deve-se observar o ciclo de vida dos mesmos ou a teoria das três idades. Nesta teoria, os documentos são inicialmente organizados, mantidos e utilizados ativamente pelos criadores, depois são armazenados por um período adicional de uso não frequente e, finalmente, quando o uso operacional termina completamente, são selecionados como de valor arquivístico e transferidos para um arquivo permanente, ou são declarados sem valor e destruídos (RONDINELLI, 2005).

Para que o processo de gestão documental seja concretizado, é necessário um profissional qualificado para administrar o fluxo de informação, aplicando técnicas de organização, recuperação e conservação da informação contida nos documentos, de modo que possibilitem seu uso com qualidade durante todo o período de vigência.

O processo final de destinação de documentos é o de maior importância e o que apresenta maior complexidade, por isso, é imprescindível o acompanhamento profissional, pois é a partir dele que se inicia o processo de disponibilizar as informações contidas nos documentos para a tomada de decisão e a comprovação de direitos e obrigações. Isso se fundamenta somente se os documentos estiverem devidamente classificados e guardados. Observa-se que a organização irá impactar no descarte ou não 
de determinado documento, pois, por mais que ele perca o valor legal, ele pode ter valor histórico para a empresa e, neste caso, não deve ser eliminado (PAES, 2004).

Tratando do aspecto histórico, é intrínseca a relação da gestão de documentos com a área de conservação dos mesmos, uma vez que os suportes físicos passam por processo de desgaste durante sua vida útil. A utilização, aliada a condições desfavoráveis de umidade, temperatura e iluminação, acelera o processo de deterioração dos documentos e contribui para a proliferação de fungos, ácaros e traças.

Além do benefício de preservação dos documentos que integram o patrimônio documental, Avagliano (2011) destaca outros benefícios da gestão documental:

- agilidade no acesso às informações e documentos públicos e privados;

- eliminação criteriosa dos documentos desprovidos de valor que não justificam seu armazenamento;

- agilidade no processo de tomada de decisões;

- agilidade no planejamento, execução, controle e avaliação das ações governamentais;

- transparência das ações administrativas.

Dentre os benefícios destacados acima, Bernardes e Delatorre (2008) reiteram, ainda, que a implantação de um processo de gestão documental pode auxiliar as organizações no controle sobre as informações produzidas e recebidas. Assim, com o uso da tabela de temporalidade, é possível obter maior controle dos documentos que devem permanecer no arquivo.

Além da relevância de arquivar os documentos, o mais importante é poder localizá-los posteriormente, de forma ágil e no momento desejado. Dessa forma, quando se enfatiza a importância de gestão documental, não se pode esquecer o papel do profissional da informação, que é o responsável pela organização e, consequentemente, pelo acesso às informações dos arquivos. Para isso, o arquivo precisa estar organizado e com um controle de qualidade ideal. Buscando esse diferencial, na próxima seção serão expostos os conceitos da filosofia $5 \mathrm{~S}$ que podem ser úteis e aplicáveis à gestão de arquivos. 


\section{5S: FERRAMENTA DE GESTÃO}

A filosofia 5S apareceu no Japão a fim de melhorar o sistema de funcionamento das instituições. Não é apenas voltada para empresas, mas também para os funcionários, a fim de contribuir para a melhoria da produtividade, qualidade e segurança, através da mobilização dos funcionários para comportamento e ações disciplinadas e contínuas (CAMPOS, 1992; LIKER, 2005).

A essência dos 5S está em mudar atitudes e condutas das pessoas no ambiente de trabalho. 0 objetivo é acrescentar eficiência à produção, motivando e conscientizando as pessoas a manterem o ambiente organizado, ordenado e acessível, gerando um clima organizacional mais saudável. Essa organização das pessoas é a base para melhorias contínuas.

Albino (2011, p. 62) destaca que "o 5S é um processo educativo que possibilita a mudança comportamental e cultural das pessoas na organização", porém lembra que "a implantação da filosofia dos 5S deve ser adaptada às características e às necessidades de cada empresa, não devendo conflitar com a cultura local.” Essa mudança comportamental com o alinhamento das necessidades de cada empresa é fundamental para que a implantação da filosofia 5S obtenha sucesso.

Cada um dos $5 \mathrm{~S}$ representa as iniciais de cinco termos japoneses que começam com a letra $\mathrm{S}$, e que indicam boas práticas para o ambiente de trabalho. Os cinco termos são:

a) Seiri (Senso de Utilização) - separar o que é útil do que não é necessário. Melhorar o uso do que é útil - ferramentas, peças, materiais, documentos, entre outros utensílios. É preciso ter habilidade para o gerenciamento pela estratificação, que é a maneira eficiente de tomar decisões quanto à frequência de uso.

b) Seiton (Senso de Ordenação) - organizar o que sobrou. Um lugar para cada coisa e cada coisa no seu lugar. Nesta etapa é preciso adotar uma metodologia de organização, definindo suportes e materiais para o arranjo dos documentos, elaborando manuais de procedimentos e definindo o layout que melhor se ajusta às áreas de trabalho.

c) Seisou (Senso de Limpeza) - limpar e evitar sujar para contribuir com o bom funcionamento dos processos. Para isso, é preciso também investigar as rotinas que geram sujeira, tentando modificá-las. 
d) Seiketsu (Senso de Saúde e Higiene) - padronizar as práticas saudáveis resultantes dos três primeiros. A melhor maneira de se conseguir isso é fazendo cumprir os prazos estabelecidos nos regulamentos, mantendo a padronização, definindo o layout, a iluminação e o mobiliário adequado ao ambiente de trabalho.

e) Shitsuke (Senso de Autodisciplina) - assumir a responsabilidade de seguir os padrões saudáveis. É de suma importância, pois enfatizar o aspecto cultural e a autodisciplina das pessoas é elemento vital para a continuidade do processo do $5 \mathrm{~S}$ (LEAN ENTERPRISE INSTITUTE, 2011; RIBEIRO, 2010; VIVER 5S, 2014).

A filosofia dos $5 \mathrm{~S}$ traz muitos benefícios, pois agrega qualidade e organização para o bom funcionamento da empresa. A base para os princípios de melhoria contínua e mudança de hábitos pode ser buscada na filosofia $5 \mathrm{~S}$ com a finalidade de criar um ambiente organizado, limpo, seguro, padronizado e com colaboradores disciplinados. Pequenas ações em direção a essa cultura podem representar no aumento de produtividade e na redução de custos associados à eliminação de desperdícios.

O programa 5S pode ser aplicado em empresas de todos os tipos, ramos e portes, e a conscientização, bem como a participação de todos os colaboradores, é fundamental ao sucesso do programa. Seguindo os passos de Naves (2013), a implantação pode ser dividida em três etapas:

a) $5 S$ Ativos: envolve a introdução dos conceitos no sentido de "colocar em ordem" o ambiente de trabalho.

b) $5 S$ Eficazes: essa etapa busca tornar um hábito a aplicação desses conceitos, mantendo a ordem conseguida por meio dos 5 S ativos, com a identificação de materiais que não são utilizados e o descarte adequado.

c) $5 S$ Preventivos: tem o objetivo de buscar a eficiência, por meio da prevenção, da aplicação dos conceitos que já se consolidaram como hábito. A prevenção é alcançada a partir da busca da melhoria contínua aplicada a cada senso. Isto se faz mediante a indagação permanente sobre quais motivos ainda levam à ineficiência e à intervenção de suas causas.

O 5S ganha muita importância principalmente em projetos que incluem grandes mudanças culturais. 0 ambiente de trabalho limpo e organizado colabora para que os operadores se sintam mais satisfeitos e o trabalho seja mais produtivo (OHNO, 2009). Com a melhoria da produtividade, é possível atender precisamente as necessidades dos clientes, que é uma das principais demandas do ambiente estudado. 


\section{MATERIAIS E MÉTODOS}

A presente pesquisa se caracteriza como uma pesquisa-ação, em que existe uma participação direta dos envolvidos na pesquisa com a solução do problema. Assim, a filosofia 5S foi aplicada nas empresas do Grupo Santa Fé.

A escolha pela aplicação de uma pesquisa-ação foi instigada pela possibilidade de se desenvolver um novo conhecimento por meio de ações práticas com a participação dos atores envolvidos. Thiollent (1997) esclarece que o foco da pesquisa-ação é diagnosticar problemas e buscar soluções para a organização. Com caráter interrogativo-crítico, o pesquisador deve conduzir os atores a formular perguntas acerca da situação em que vivem no ambiente de trabalho, promovendo ampla interação entre pesquisadores e membros representativos da situação investigada.

Em relação à natureza das variáveis pesquisadas, caracteriza-se por ser uma pesquisa quali-quantitativa. Segundo Roesch (2000), as pesquisas qualitativas e quantitativas se complementam. A primeira estimula o pesquisador a falar livremente sobre o tema, visando a uma maior compreensão do leitor, e a segunda apura opiniões e atitudes de forma objetiva, através de análises numéricas.

Devido à necessidade de se conhecer alguns aspectos relacionados à gestão documental e da informação do Grupo Santa Fé, o estudo se classifica como exploratório e descritivo. No entendimento de Andrade (2003, p. 124), a pesquisa exploratória é o primeiro passo de todo trabalho científico. Já a pesquisa descritiva para Alves (2006, p. 52) “[... tem como objetivo primordial a descrição das características de determinada população ou fenômeno ou o estabelecimento de relações entre fenômenos". 0 uso dessa técnica é essencial para mapear as atividades que compõem os dois processos estudados do setor de despachante e fazer uma descrição do ambiente e da população em estudo.

\subsection{UNIVERSO DA PESQUISA}

Com o objetivo de aplicar o 5S na gestão de arquivos, optou-se por desenvolver a pesquisa no arquivo do Grupo Santa Fé. O Grupo conta atualmente com onze empresas ativas, gerando cerca 2.500 empregos diretos e indiretos, atuando em setores como: comercialização de veículos, administração de consórcios, construção civil, hotelaria e administração de shopping centers. 


\subsection{PROCEDIMENTOS DE ANÁLISE DOS DADOS}

Durante o procedimento de análise dos dados, identificou-se a necessidade de estabelecer métricas que permitissem ter uma melhor avaliação das técnicas implantadas.

A criação de métricas para avaliar os resultados é necessária para avaliar se a implantação da filosofia $5 \mathrm{~S}$ trouxe ou não resultados significativos à organização estudada. Para mensurar os ganhos relacionados aos resultados, a aplicação da pesquisa teve como fundamento a análise do parâmetro lead time, com a finalidade de mensurar os tempos de recuperação da informação antes e depois da aplicação do método proposto. A fórmula do lead time é calculada da seguinte forma:

\section{Lead time: tempo de processamento + tempo de retenção}

Tempo de processamento: tempo gasto para processar as atividades.

Tempo de retenção: tempo em que o material fica parado, esperando ser processado.

Para saber se a recuperação dos documentos está sendo feita de acordo com a demanda do cliente, foi utilizado o Takt time, também conhecido como Tempo Takt, responsável por projetar o trabalho com a avaliação especificada e no ritmo exigido pelo cliente.

\section{Takt time $=\underline{\text { Tempo total disponível }}$ Demanda do cliente}

Outra métrica considerada é a financeira, com objetivo de medir os custos atuais e os futuros para desempenhar o processo. A última métrica considerou o espaço físico, tendo em vista que o arquivo atual já não suporta mais o crescimento documental, e o aluguel de novo espaço iria gerar um custo adicional, que não é parte do plano orçamentário do Grupo.

\section{APRESENTAÇÃO E ANÁLISE DOS RESULTADOS}

Um dos grandes problemas levantado na fase inicial da pesquisa refere-se ao tempo elevado de retorno do arquivista para atender alguns pedidos de documentos, 
cujo grau de dificuldade de localização é maior. Isto ocorre porque alguns pedidos não apresentam data de entrada exata ou possuem algum dado inconsistente com o sistema; logo, é preciso uma busca mais abrangente para localizá-los. Por atender a todas as empresas e não dispor de mais funcionários para auxiliar, o tempo médio de retorno desses processos críticos, com uma solicitação de até 10 documentos, é de seis horas. Entretanto, muitos pedidos são urgentes, uma vez que o cliente precisa de imediato do documento, e nem sempre é possível cumprir essa exigência, pois a busca por esses processos críticos acaba atrasando também os de fácil localização, que poderiam ser atendidos no mesmo instante.

Para melhorar esse tempo de retorno, fez-se uma reorganização do espaço físico, com a finalidade de preconizar uma gestão organizada e limpa dos ambientes e das ferramentas, bem como de alguns documentos, pensando no menor desperdício de tempo e no menor deslocamento para busca. Para operacionalizar essa condição, optouse pelo uso da ferramenta $5 \mathrm{~S}$, uma vez que os resultados são rápidos e de fácil visualização.

\subsection{A IMPLANTAÇÃO DA FERRAMENTA 5S NO ARQUIVO}

A implantação da ferramenta 5S no arquivo foi desenvolvida por partes, levando em consideração a sequência de cada $S$, conforme descrito nos resultados a seguir.

\subsubsection{Seiri (Senso de Utilização)}

Para cumprir esta etapa, fez-se um levantamento de materiais de escritório e documentos que não seriam utilizados e poderiam ser descartados.

Para o descarte dos documentos, consultaram-se a legislação e a tabela de temporalidade, para verificar o tempo de guarda de cada tipo de documento. Após a finalização da lista, foi preciso a aprovação dos gerentes de todos os setores envolvidos no descarte. Alguns tipos de documentos, mesmo sem valor legal, podem ser úteis para suprir a necessidade dos clientes, por isso a importância de aprovação dos gerentes, pois são eles que estão em contato com os clientes externos e sabem melhor de suas necessidades. Aprovada pelos setores, a relação foi apresentada para o proprietário da empresa, que fez, por escrito, a liberação do descarte dos documentos relacionados. 
A relação dos documentos aprovada pela diretoria compreende 1130 caixas de arquivos, o que corresponde a mais de oito toneladas de papel, conforme apresentado na figura 1:

Figura 1 - Documentos descartados para reciclagem.

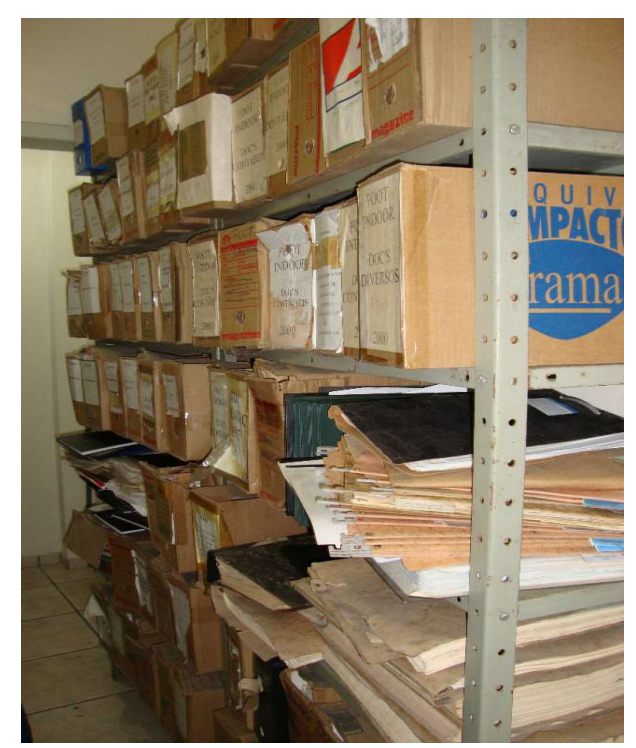

Fonte: Dados primários (2017).

O descarte desses documentos foi feito por uma empresa especializada em reciclagem. Foi necessário que o arquivista e mais um auditor da empresa acompanhassem o trabalho de picoteamento dos documentos, pois muitos eram confidenciais e, por segurança, deveriam ser destruídos antes de serem reciclados.

Após o descarte dos documentos, uma vistoria foi feita a fim de eliminar do local de trabalho tudo que não era mais necessário relacionado ao material de escritório, cuidando para não jogar fora o que ainda poderia ser útil. Assim, objetos que ainda poderiam ser utilizados foram realocados para outros setores da empresa. A figura 2 ilustra o material de escritório que foi eliminado ou retirado do setor de arquivo. 


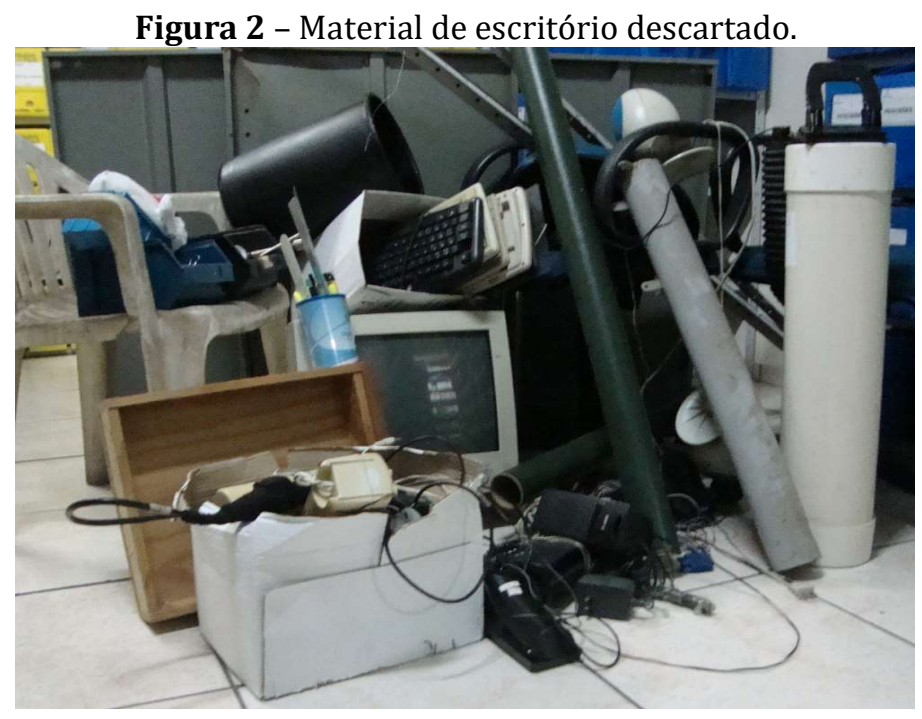

Fonte: Dados primários (2017).

A figura 2 ilustra uma grande quantidade de objetos quebrados, presentes no arquivo e que não tinham mais utilidade. Os objetos sem utilidade foram enviados para reciclagem, e os que poderiam ser úteis foram enviados ao departamento de compras para realocação em outros setores.

Com a retirada dos objetos, o ambiente do arquivo ficou mais limpo e livre para o arquivista exercer suas funções. As figuras 3 e 4 ilustram essa mudança:

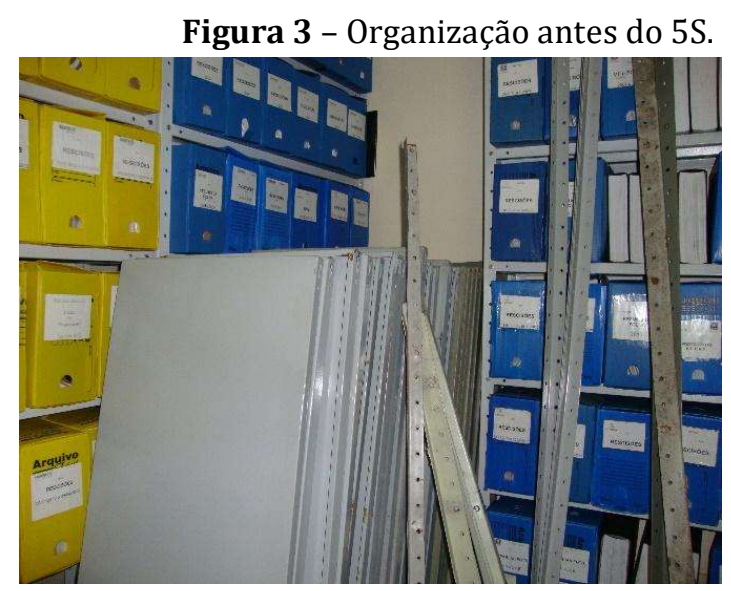

Figura 4 - Organização após 5S.

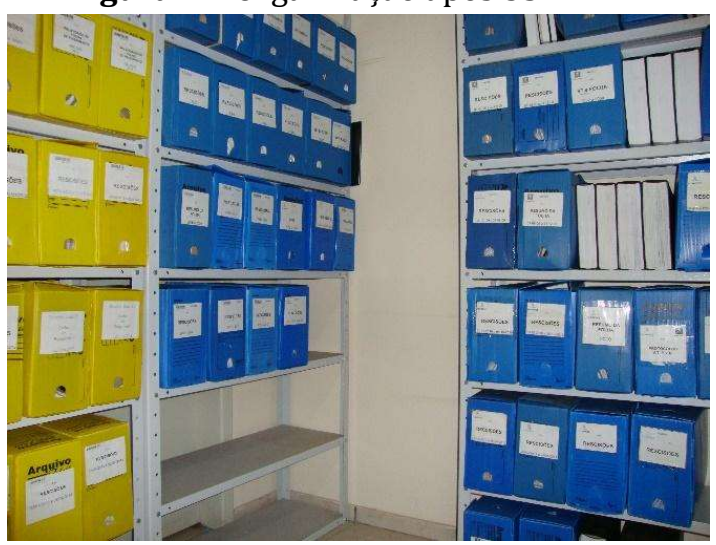

Fonte: Dados primários (2017).

Para a recuperação de algum documento, era preciso retirar os objetos. Esta tarefa extra acarretava em uma demora maior no atendimento do pedido do cliente. Com a retirada desses objetos, o trabalho do arquivista pode ser feito de forma mais eficiente, configurando mais agilidade no atendimento do cliente.

Com o primeiro $S$ implantado, já é possível observar alguns benefícios como: 
- mais espaço para guarda de novos documentos;

- maior espaço para busca de documentos, sem objetos atrapalhando o trajeto;

- menos desperdício com relação ao material de escritório;

- mais organização.

\subsubsection{Seiton (Senso de Ordenação)}

$\mathrm{O}$ segundo $\mathrm{S}$ consiste em ordenar materiais e informações úteis de maneira funcional, para que o acesso ao que se deseja seja o mais rápido possível. Neste sentido, identificou-se que seria necessário fazer uma reordenação dos documentos distribuídos no arquivo, para que os mais utilizados ficassem localizados mais próximos da sala do arquivista e, portanto, fossem rapidamente acessados.

A primeira mudança foi no armário em que há um arquivo funcional dos colaboradores ativos. 0 armário é constantemente acessado para identificar advertências de funcionários, incluir pastas de novos funcionários e excluir informações dos que são desligados. Este se encontrava a uma distância de 18 metros da sala do arquivista e, a fim de proporcionar velocidade à busca, foi posicionado dentro da mesma, conforme pode ser observado na figura 5. Assim, o desperdício de tempo para chegar até o armário passou a ser quase nulo.

Figura 5 - Localização do arquivo funcional.

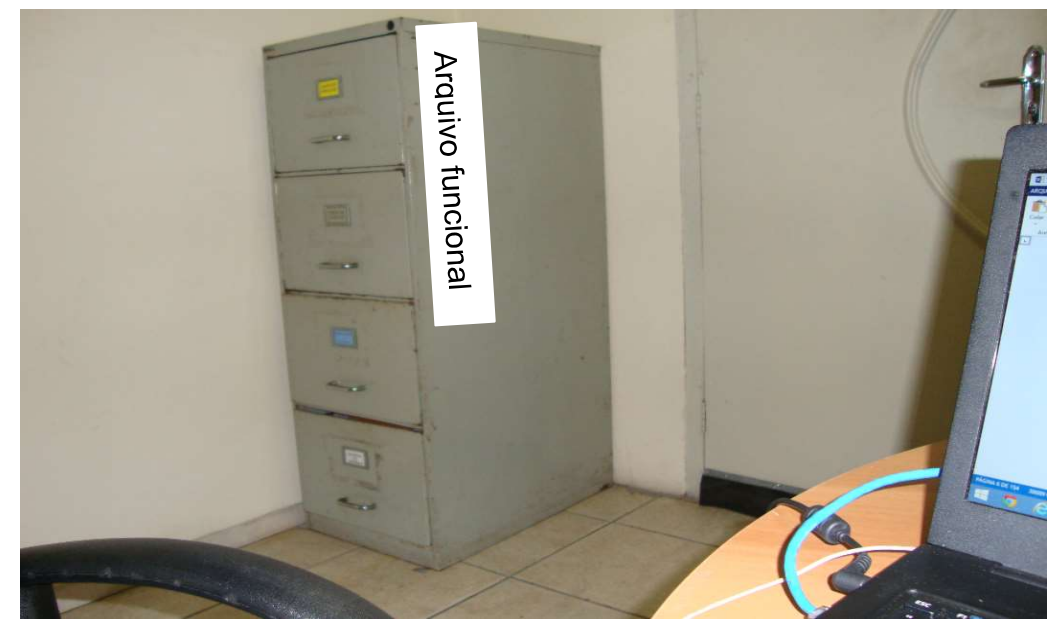

Fonte: Dados primários (2017).

Outra mudança foi identificar para qual empresa há maior solicitação de documentos. Por meio dos protocolos, foi possível contabilizar que a Florence Peugeot é 
a que possui maior demanda, representando cerca de $50 \%$ a mais que a Ponto Um Veículos, empresa cujas informações estão em uma sala ao lado do escritório do arquivista, possuindo acesso mais rápido. Assim, foi possível constatar que deveria haver uma inversão da localização dos documentos das duas empresas, pois a Florence Peugeot está, atualmente, na sala mais distante do escritório. Essa mudança ainda está sendo planejada, pois envolve a troca de quatro mil caixas de arquivo e requer ajuda de outros profissionais.

A última mudança deste senso foi confeccionar uma etiqueta na entrada de cada sala, informando qual empresa encontra-se arquivada em cada uma. Além de identificar o nome da empresa, a etiqueta foi impressa colorida, com a mesma cor da caixa que corresponde à empresa. Desse modo, em uma busca documental na sala dois para a empresa Santa Rosa, será possível identificar mais rápido quais caixas pertencem a ela, por ser a única que apresenta caixas vermelhas.

Figura 6 - Etiquetas de identificação das salas.

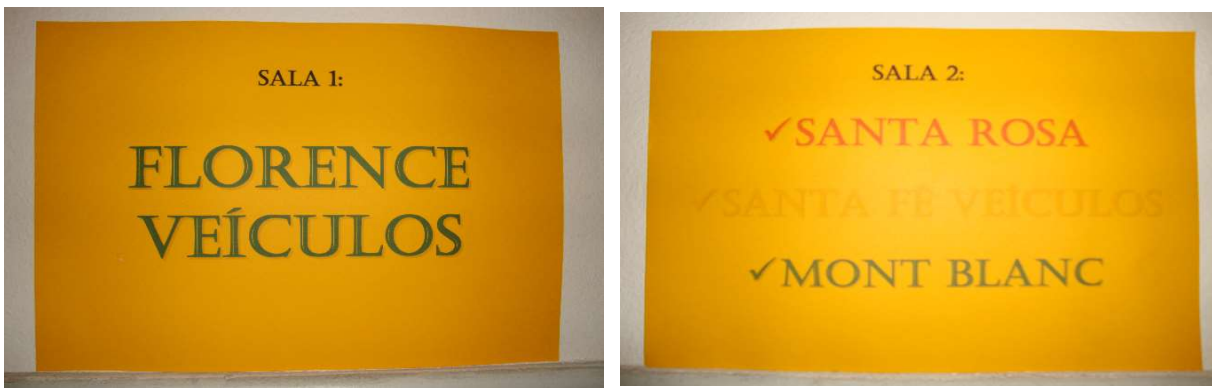

Fonte: Dados primários (2017).

Como o arquivo é composto por cinco salas, quatro que servem para armazenar a documentação e uma sendo o escritório do arquivista, a identificação visual agiliza a localização dos documentos da empresa, proporcionando redução de movimentação e espera.

\subsubsection{Seisou (Senso de Limpeza)}

Quanto à limpeza do ambiente do arquivo, já são realizadas faxinas semanais e um controle de pragas com desinsetização e desratização uma vez por ano. No entanto, é preciso um controle maior, pois, como não há um dia exato para faxina, houve semanas em que não foi feita. Além disso, o controle de pragas perdia a eficácia próximo ao 
vencimento, e alguns insetos, como baratas, podiam ser visualizados. Para aumentar esse controle, consultou-se uma empresa especializada que sugeriu a desinsetização a cada seis meses. Logo, foi feita uma reprogramação com o setor administrativo para atender a esta necessidade. Para resolver o problema da limpeza, programou-se com o setor responsável que toda segunda à tarde seria feita uma faxina geral no arquivo e haveria o recolhimento do lixo do ambiente em todo final de tarde.

Quanto à limpeza dos documentos, iniciou-se uma higienização dos relativos aos Recursos Humanos, pois são os que necessitam de um tempo de guarda maior, superior a 25 anos. 0 objetivo é a substituição dos grampos trilho de metal e a retirada de grampos em excesso, conforme ilustrado nas figuras 7 e 8. Isto foi necessário, pois, com o tempo, estes grampos de metal oxidam, criando ferrugem, que deteriora o documento e dificulta o seu manuseio.

Figura 7 - Documentos antes do 5S.

Figura 8 - Documentos após 5S.
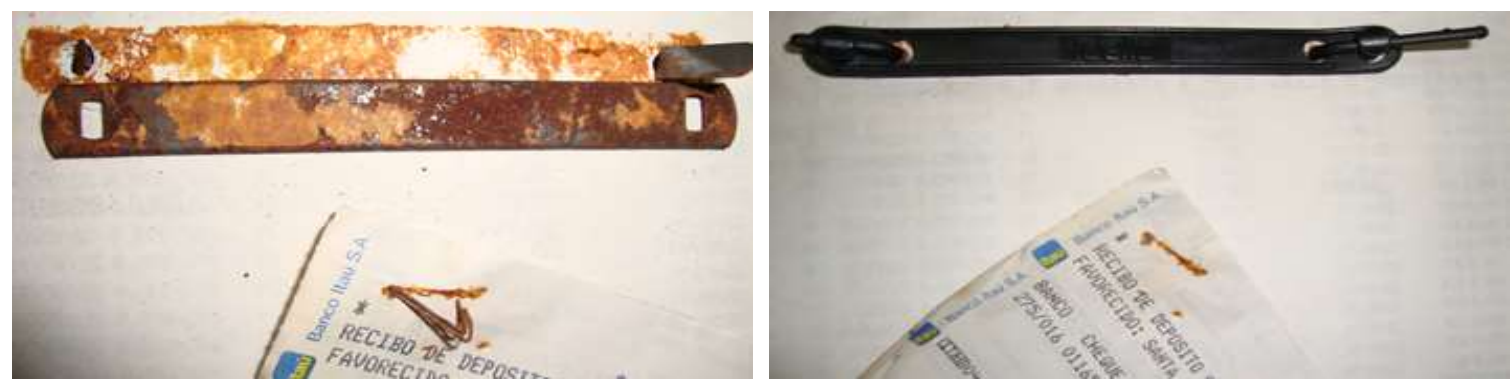

Fonte: Dados primários (2017).

Com a higienização, a recuperação de um documento torna-se mais rápida, pois o grampo trilho de metal é mais difícil de ser retirado e incluído novamente e, com a ferrugem, esta dificuldade aumenta. Já o grampo trilho de plástico, além de ser mais fácil de manusear, não deteriora o documento.

\subsubsection{Seiketsu (Senso de Saúde e Higiene)}

O quarto senso foi instituído com a preocupação de implantar e manter boas condições de trabalho, de forma a favorecer a saúde física e mental do trabalhador. Inicialmente, houve a preocupação com a ergonomia do trabalhador. Então, substituíram-se a mesa do escritório e a cadeira, pois não forneciam o conforto ideal para o desenvolvimento das atividades. Em seguida, instalaram-se mais 5 jogos de lâmpadas fluorescentes a fim de que o ambiente tivesse a iluminação adequada. Por fim, 
colocou-se uma fita feltro nas extremidades da porta que dá acesso ao escritório, pois ela fica ao lado da oficina de uma concessionária e fortes ruídos podiam ser ouvidos. Com estas medidas, o ambiente ficou mais silencioso e agradável.

Figura 9 - Escritório antes do 5S.

Figura 10 - Escritório após 5S.
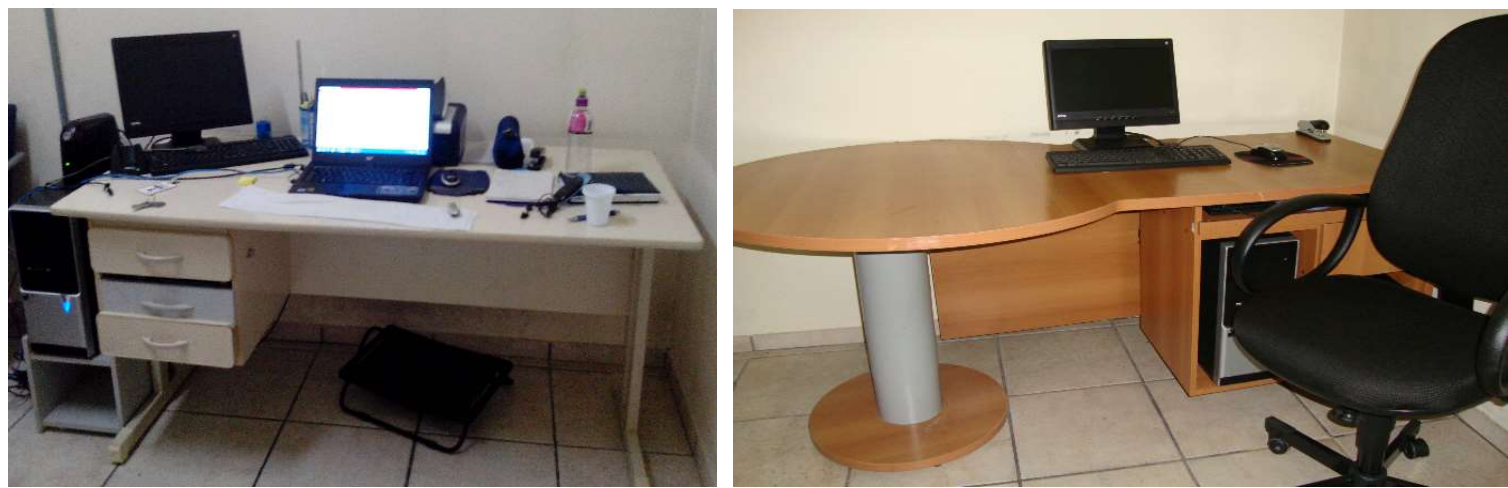

Fonte: Dados primários (2017).

A substituição da mesa e cadeira do escritório, aliada à reorganização do material de expediente, possibilitou um ambiente mais limpo e saudável, com menos entraves para a realização das atividades.

\subsubsection{Shitsuke (Senso de Autodisciplina)}

O quinto senso está sendo implantado diariamente no setor de Arquivo. É necessário um olhar mais crítico de todos os detalhes que envolvem o setor, pensando sempre num ambiente mais agradável e com menos desperdícios, seja material ou temporal, até se tornarem hábitos cotidianos. A autodisciplina é uma qualidade que precisa ser desenvolvida diariamente para que as melhorias conseguidas com os quatro primeiros S sejam sustentáveis e novas melhorias possam ser implantadas.

\subsection{AVALIAÇÃO DA IMPLANTAÇÃO DA FERRAMENTA 5S NO ARQUIVO}

Com a implantação dos 5S, podem-se vislumbrar alguns benefícios, além daqueles apresentados na seção 5.1:

- mais motivação do colaborador, devido às melhorias no ambiente de trabalho;

- mais produtividade, uma vez que é possível ser mais eficiente no desenvolvimento das atividades com o ambiente ordenado; 
- redução dos desperdícios com relação ao material de escritório;

- ambiente de trabalho mais limpo e higiênico;

- redução do tempo de respostas aos clientes.

A busca deste último benefício foi um dos motivos que impulsionaram a aplicação desta ação e, mesmo que ainda esteja em andamento, já é possível medir o ganho com a reorganização do espaço físico, que culminou na redução do tempo de retorno ao cliente, conforme descrito a seguir:

\section{Lead time: tempo de processamento + tempo de retenção}

- Lead time do estado atual: $6 \mathrm{~h}+0 \mathrm{~h}$ Lead time: $6 \mathrm{~h}$

- Lead time do estado futuro: $3 \mathrm{~h}+0 \mathrm{~h}$ Lead time: $3 \mathrm{~h}$

O lead time foi calculado a partir de três testes realizados antes e após a aplicação dos 5S, que correspondem, respectivamente, ao resultado do lead time do estado atual e do lead time do estado futuro. Nestes testes, era necessário localizar até 10 documentos com alto grau de dificuldade de localização. 0 tempo de retorno ao cliente foi reduzido em 50\%, passando de 6 para 3 horas de duração. Logo, com a aplicação dos 5S, foi possível diminuir significativamente o tempo gasto com as atividades que não agregavam valor ao processo.

Com a conclusão, faz-se necessário calcular novamente o Takt time do processo para ver se a demanda do cliente, após o 5S, está sendo atendida no instante desejado.

\section{Takt time $=\underline{\text { Tempo total disponível }}$ Demanda do cliente}

Takt time $=$ $180 \min$ 10

Takt time = 18 min para recuperação de cada documento.

Com o tempo de recuperação dos documentos reduzido em 50\%, é possível, ainda, atender a demanda do cliente sem a contratação de novos funcionários. 


\begin{tabular}{|c|l|c|}
\hline \multicolumn{3}{|c|}{ Resultado final da aplicação do 5S } \\
\hline $\begin{array}{c}\text { Economia } \\
\text { de tempo }\end{array}$ & \multicolumn{1}{|c|}{ Economia financeira } & $\begin{array}{l}\text { Economia do } \\
\text { espaço físico }\end{array}$ \\
\hline \multirow{3}{*}{$180 \mathrm{~min}$} & $\begin{array}{l}\text { Colaborador: } 180 \mathrm{~min} \times 0.273: \mathrm{R} \$ 49,14 \\
\text { Aluguel: } 31,7 \mathrm{~m}^{2} \times 8,5 \times 12 \mathrm{~m}:\end{array}$ & \\
$\mathrm{R} \$ 3.233,40$ & $31,7 \mathrm{~m}^{2}$ \\
& $\begin{array}{l}\text { Estantes: } 31 \times 160,00: \\
\mathrm{R} \$ 4.960,00 \\
\text { Total: }\end{array}$ & \\
\hline
\end{tabular}

O cálculo da economia financeira do colaborador foi feito sobre o custo de um funcionário em regime da CLT. O salário médio deste funcionário é de R $2.000,00$, somando-se, ainda, $80 \%$ de encargos, resultando em um custo de $\mathrm{R} \$ 0.273$ por minuto. A economia financeira do aluguel das salas, estantes, assim como do espaço físico, foi calculada a partir da reciclagem das 1130 caixas de arquivos realizada no primeiro senso. Para o cálculo do aluguel, foi considerado custo mensal do aluguel de $\mathrm{R} \$ 8,5 / \mathrm{m}^{2}$ e estimado que as caixas abrangessem uma área de 31,7 $\mathrm{m}^{2}$. Então, fez-se a projeção em 12 meses, para verificar a economia anual com a reciclagem dos documentos que não possuíam valor legal. Referente ao cálculo das estantes, a reciclagem contribuiu para liberar espaço em 31 estantes, que não precisarão ser compradas para suportar os novos documentos. Com o valor de mercado de $\mathrm{R} \$ 160,00$ por estante, a economia financeira chegou a $\mathrm{R} \$ 4.960,00$.

O representativo valor da economia financeira desta ação reflete na importância de se preocupar tanto com a geração de novos documentos quanto com os que já existem e, principalmente, no ambiente que estão armazenados. É imprescindível seguir a tabela de temporalidade dos documentos, descartando os que já não possuem mais valor legal de guarda, pois o preço que se paga para manter os documentos sem serventia é muito alto e desnecessário. Para seguir rigorosamente o descarte anual, projetou-se para que fosse feito, em todo mês de janeiro, o descarte de documentos que perderam a validade legal.

\section{CONSIDERAÇÕES FINAIS}

O estudo apresentado mostrou o processo de implantação da filosofia $5 \mathrm{~S}$ em um arquivo empresarial. 0 objetivo inicial deste trabalho foi alcançado, uma vez que foi apresentada e discutida toda a implantação da ferramenta 5S na empresa descrita. 
O aprofundamento na literatura brasileira e estrangeira, acerca dos conceitos e princípios da filosofia 5S, norteou este trabalho para alcançar os objetivos preestabelecidos e ajudou a solucionar o problema de pesquisa. A realização de uma leitura crítica de textos científicos possibilitou a instigação do pesquisador. Assim, exemplos do sucesso da aplicação em outras áreas foram estudados e adaptados para a aplicação desses conceitos na gestão do arquivo.

Entre os principais resultados, pode-se citar uma redução do tempo médio para busca dos documentos, uma economia do espaço físico e uma considerável economia financeira. A reorganização de documentos e objetos e a eliminação dos que não possuíam mais valor legal liberaram uma área livre no arquivo de $31,7 \mathrm{~m}^{2}$, o que possibilitou o arquivamento de mais de 1000 caixas de documentos. Tal resultado é expressivo e importante para o momento atual do arquivo, uma vez que ele já estava atingindo a sua lotação máxima.

O uso do método para executar melhorias na gestão de arquivos gerou resultados acima do esperado, considerando as análises realizadas. Uma das hipóteses da obtenção destes resultados representativos está relacionada ao fato de que poucos estudos, atualmente, são direcionados a melhorar a prática da gestão de arquivos. Poucas empresas demonstram interesse em melhorar setores que são considerados atividadesmeio, que é o caso do arquivo na maioria das organizações. Neste sentido, a gestão da informação ainda tem muito a evoluir, e novas pesquisas podem proporcionar ganhos ainda maiores, contribuindo não somente para melhorar a gestão no arquivo, mas também na empresa como um todo, já que é um local que tem relação com todos os setores da empresa.

Diante dos resultados apresentados, entende-se que os conceitos do $5 \mathrm{~S}$ podem ser aplicados de forma eficiente na gestão de arquivos, implementados como forma de eliminar desperdícios e tornar os processos, que dependem das informações ali contidas, mais eficientes. Essa iniciativa demonstra que a gestão documental deve ser bem estruturada nas empresas, permitindo que seja vista e empregada como oportunidade de ampliação das ações estratégicas, e não apenas como forma de atendimento às demandas legais, relacionadas à salvaguarda de documentos.

Em termos de geração de novos conhecimentos, este estudo mostrou que a aplicação dos princípios do 5S na área de gestão de arquivo possibilita que problemas antigos sejam resolvidos a partir de novas soluções. Para o proponente da pesquisa e 
todos os envolvidos no estudo, foi uma oportunidade de aprender novos conceitos e novas práticas de trabalho. 0 grande desafio com o término do estudo é sustentar as melhorias alcançadas e buscar sempre novas oportunidades de melhoria, a fim de que novas técnicas e ferramentas possam surgir para aprimorar cada vez mais a eficiência na gestão de arquivos.

\section{REFERÊNCIAS}

ALBINO, Maria de Fátima Vollet. A utilização do Lean Office (escritório enxuto) em ambiente público-administrativo. 2011. 104 f. Dissertação (Mestrado em Engenharia Mecânica) - Universidade de Taubaté, Taubaté, 2011.

ALVES, Magda. Como escrever teses e monografias: um roteiro passo a passo. São Paulo: Campus, 2006.

ANDRADE, Maria Margarida. Introdução à metodologia do trabalho científico: elaboração de trabalhos na graduação. 6. ed. São Paulo: Atlas, 2003.

AVAGLIANO, Eliana Martinelli et al. Implementação do programa de gestão documental itinerante na administração direta estadual. 2011. Disponível em: <http://foruns.bc.unicamp.br/Arquivos\%20Bibioteca\%20Virtual/Palestras/1509/Eliana.Apresenta\%C3\%A7\%C3\%A30\%20Forum\%20UNICAMP_15-09-11.pdf>. Acesso em: 12 mar. 2017.

BERNARDES, Ieda Pimenta; DELATORRE, Hilda. Gestão documental aplicada. São Paulo: Arquivo Público do Estado de São Paulo, 2008.

BRASIL. Lei n. 8.159, de 8 de janeiro de 1991. Dispõe sobre a política nacional de arquivos públicos e privados e dá outras providências. Diário Oficial da União, Brasília, DF, 09 de jan. 1991. Disponível em:

<http://www.planalto.gov.br/ccivil_03/leis/L8159.htm>. Acesso em: 12 mar. 2017.

CAMPOS, Vicente Falconi. TQC - Controle da Qualidade Total. 2. ed. Belo Horizonte: Bloch Editores, 1992.

CONARQ - Conselho Nacional de Arquivos. Modelo de requisitos para sistemas informatizados de gestão arquivística de documentos (E-ARQ Brasil). Brasília, 2006. 133p. Disponível em: <http://www.conarq.arquivonacional.gov.br/Media/publicacoes/ear qbrasilv1.pdf>. Acesso em: 12 mar. 2017.

LEAN ENTERPRISE INSTITUTE. Léxico Lean: glossário ilustrado para participantes do Pensamento Lean. 4. ed. São Paulo: Lean Institute Brasil, 2011.

LIKER, Jeffrey K. 0 modelo Toyota: 14 princípios de gestão do maior fabricante do mundo. Porto Alegre: Bookman, 2005. 
; HOUSEUS, M. A cultura Toyota: a alma do modelo Toyota. Porto Alegre:

Bookman, 2009.

MORENO, Nádina Aparecida; BARTALO, Linete (Org.). A gestão de arquivologia: abordagens múltiplas. Londrina: EDUEL, 2008.

MORGAN, David L. Focus group as qualitative research. London: Sage, 1997.

NAVES, Paula Vanessa Passos. Aplicação dos conceitos de 5S em um sistema de gestão de estoques de uma indústria de móveis e seus impactos na racionalização de recursos.

Revista Especialize On-line IPOG, Goiânia, 5. ed., v. 1, n. 5, jul. 2013. Disponível em: <file://C:/Users/Marcelo\%20Cavaglieri/ Downloads/ce88c2c452 8491c12369e98feb0e7fb0.pdf>. Acesso em: 12 mar. 2017.

NISHITANI, Paulo Kiyoshi. Gestão Documental em Agências Bancárias: estudo de caso em um banco da cidade de londrina. 2010. 146 f. Dissertação (Mestrado

Profissional em Gestão da Informação) - Universidade Estadual de Londrina, Londrina, PR., 2010.

OHNO, Taiichi. Workplace management. Publisher: Gemba Press, 2009.

PAES, Marilena Leite. Arquivo: teoria e prática. 3. ed. rev. e ampl. Rio de Janeiro: Editora FGV, 2004.

RIBEIRO, Haroldo. Guia de Implantação do 5S. São Caetano do Sul: PDCA Editora, 2010.

ROESCH, Sylvia Maria Azevedo. Projetos de estágio e de pesquisa em administração. São Paulo: Atlas, 2000.

RONDINELLI, Rosely Cury. Gerenciamento arquivístico de documentos eletrônicos: uma abordagem teórica da diplomática arquivística contemporânea. 4. ed. Rio de Janeiro: FGV, 2005.

THIOLLENT, Michel. Pesquisa-ação nas organizações. São Paulo: Atlas, 1997.

VALENTIM, Marta Lígia Pomim (Org.). Gestão Documental em Ambientes Empresariais. In: ___ Estudos avançados em Arquivologia. Marília: Oficina Universitária; São Paulo: Cultura Acadêmica, 2012.

VIVER 5S. 0 que é 5S. 2014. Disponível em: <http://5s.com.br/2/o-que-e-5s.php>. Acesso em: 12 fev. 2015. 


\section{SOBRE OS AUTORES}

\section{Marcelo Cavaglieri}

Mestre em Gestão de Unidades de Informação pela Universidade do Estado de Santa Catarina (UDESC). Bibliotecário do SENAC.

E-mail: marceloglieri@yahoo.com.br

\section{Jordan Paulesky Juliani}

Professor do Programa de Mestrado Profissional em Gestão da Informação da UDESC.

E-mail: jordanjuliani@gmail.com

Recebido em: 14/03/2017; Revisado em: 28/04/2017; Aceito em: 04/05/2017.

\section{Como citar este artigo}

CAVAGLIERI, Marcelo; JULIANI, Jordan Paulesky. Implantação do sistema 5s na gestão de arquivos.

Informação em Pauta, Fortaleza, v. 2, n. 1, p. 73-95, jan./jun. 2017. 